\title{
Presumed Consent for Organ Donation: Is it as Simple as it Sounds?
}

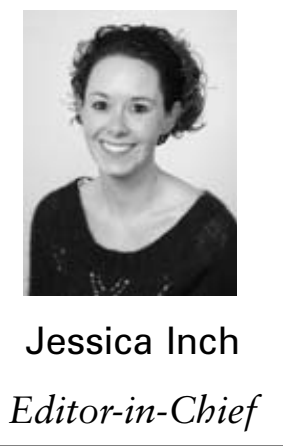

A $t$ the beginning of the year, Gordon Brown called for a national debate regarding whether we should opt 'out', rather than 'in' to the British organ donation scheme. He believes that thousands of lives would be saved if the country were to switch to this system, as waiting time for an organ is at a record high with more than 8000 people awaiting donation. He believes that a system of this kind has the potential to close the aching gap between the benefits of transplant surgery in the UK and the limits imposed by our current system of consent.

The current system in place is an 'opt in' system, whereby an individual gives consent during his or her lifetime by carrying a card, or by the preferred method of signing the register. However, it is ultimately the relatives who still make that final decision, as they are asked whether the individual could have recently changed their mind. Having to make this decision can cause tremendous pain for a relative. The result is that Britain is left with only 12.9 donors for every million. You can therefore assume that the majority refuse to donate.

This recent debate of presuming everyone wants to donate unless registered otherwise has undoubtedly been fuelled by the similar system currently running in Spain. When looking closely at their procedures it becomes clear that great emphasis is placed on the initial contact between a designated transplant team and the grieving family. Every hospital has a transplant coordinator, often a member of the surgical team, whose job it is to work closely with intensive and emergency care teams enabling them to identify potential donors. Once organ donation becomes an issue for a family, the coordinators allocate as much time as the family require with great emphasis being placed on the wishes of the deceased individual with the team asking the question: 'What do you think they would have wanted?' Nothing is held back in terms of making it very clear to the family, exactly what donation would mean for another individual, the importance of the decision they are to make and that lives depend on them. This system is very much a success story, as Spain has one of the highest donation rates in the world, with some Spanish hospitals having a refusal rate of as little as 3\%. Currently they have 35 donors for every million in its population, which is roughly three times that of Britain.

At first glance this proposed system looks like a great solution and the answer to many prayers, but some argue that presumed consent is actually no consent at all, with many patient-led groups speaking out against this system. Roger Goss, Co-Director of Patient Concern, has declared in the past that organ donation should be an altruistic gift that people should make freely and asks 'how can you have consented to something by failing to consent? Presumed consent, which normally means uninformed consent, relies on inertia to force a desired result.'

The British Medical Association is clear in supporting the proposal of assuming that everyone consents to 
donation unless they have registered otherwise and suggests that this does not mean ignoring the family's wishes. They support a 'soft' system of presumed consent, so called because it still may result in no organ donation. Currently, relatives are asked for consent, but under a 'soft' system, they would be told that their relative had not opted out of the scheme. The donation would then continue unless the relatives could prove the individual strongly disagreed with it during life but never registered, or that it is clear that to proceed would cause the family major distress. The British Medical Association continues to lobby for a change in legislation and believes that not enough is being done to make the public aware of the choices to be made.

Whether you are reading this believing the 'opt out' system to be the answer, or you think that the moral implications are being ignored, it cannot be denied that this would thrust this issue into the spotlight, creating a vast self-awareness of ones own beliefs and prompting family discussion. Writing this forced me to think long and hard about my own decision. The current research states that the minority of people verbally opt in for donation, but less than one-quarter officially register this. If the majority say they are willing, then the system of presumed consent would be more likely to respect the wishes of the masses.

This is a vast subject that I cannot hope to discuss fully here, but urge you to think carefully about your position, both personally and professionally, keeping abreast of the developments. The Chief Medical Officer for England, Sir Liam Donaldson, has asked the Organ Donation Taskforce to view presumed consent as an ongoing project. He expects a report by summer 2008 .

For more information about the current system you can take a look at the UK transplant website: www.uktransplant.org.uk 